\title{
Development and implementation of a mental development programme for young elite tennis players
}

\author{
Maxime Rome-Gosselin \\ University of Sherbrooke, Quebec, Canada.
}

\begin{abstract}
This study was conducted with two young Canadian elite tennis players. An eightweek practical work was conducted with the aim of acquiring new knowledge in sports psychology, and then applying these notions in several competitive situations. Specifically, we focused on the control of thoughts during the 25 -second break between rallies. The players were taught a specific mental routine that they had to perform between each point. In terms of results, there was a very interesting trend after analysing the data collected. When players did not perform their pre-set routine before a rally, they had more than $50 \%$ chance of losing the next point by making an unforced error.
\end{abstract}

Key words: sports psychology, mental routine, thought control

Received: 10 June 2021

Accepted: 30 June 2021

Corresponding author:

Maxime Rome-Gosselin. Email: maximeromegosselin@gmail.com

\section{INTRODUCTION}

In tennis, mental toughness is often the aspect that makes the difference between winning and losing (Cowden, 2016). Indeed, our sport requires an extraordinary level of concentration and mental involvement. But why in tennis more than in any other sport? In fact, on average, out of 60 minutes of play on court, a player will only really hit the ball for 12 minutes (Vaillant, 2008). Therefore, the other 48 minutes will be devoted to time between points and side changes. All these 'dead' times are then pivotal moments where the players can escape through inappropriate thoughts that have no place in a winning process. Ironically, the players may simply lose the game when they are not playing. It is then essential, that the coach mentally guides their players during these moments of waiting. That is why it was decided to provide the players with a specific mental routine to perform between each rally. Then it was tested if the mental routine had an impact on the outcome of the next point.

This technique is inspired by the work of Mamassis and Doganis (2004), Vaillant (2008) and Morais and Gomes (2019).

\section{DETAILED DESCRIPTION OF THE MENTAL ROUTINE BETWEEN RALLIES}

First of all, it is important to understand that there are only four possible situations following a rally in tennis. Here is an explanation of the desired reactions to each of the four situations.

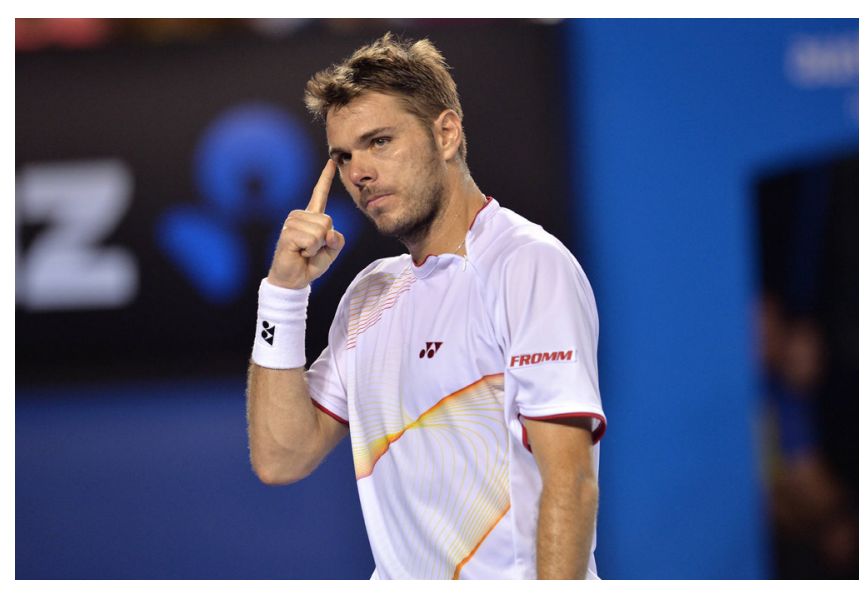

Situation 1: The player wins the point because the opponent made a mistake.

Sometimes you win points without having earned them. This is very common in tennis. Be opportunistic, take advantage of the opportunity. As they say, tennis is too stingy and thankless a game to be picky. So, congratulate yourself, but discreetly and above all, it is important not to denigrate yourself.

Second situation: The player wins the point, because they made a good shot.

You have just won a "super" point. Let yourself be overwhelmed by the positive emotion that comes with it: pleasure, pride, a sense of achievement, etc. Afterwards, it is important to mark the point literally with a positive anchor (clenching your fist, verbal encouragement, etc). 
Third situation: The player loses the point because the opponent made a good move.

You have just lost the point, but you are still playing very well. Take a deep breath to release any frustration and then look for the positive side of the situation: "No regrets, I did my best". Occasionally we can even applaud the opponent and say, for example, "Well done, good shot".

Fourth situation: The player loses the point because they make a mistake

You have just lost the point because of something you did: bad footwork, lack of concentration, bad choice, etc. Instead of sinking into a negative emotion that will be very difficult to get out of and will not help you at all, say something detached to yourself such as: "Everyone misses, even Federer", "This proves that I am human", etc. Then, in a vacuum, do the move you wish you had done, visualise the ball where you would have liked it to go, and move on. This is called a neutral anchor.

So, for these four situations, the first five to ten seconds after a rally will be spent analysing the situation and the reaction that needs to happen. Thereafter, the players should think about the next move. If the player is serving, they should decide which serve they are going to use as a first serve, as well as on the second serve. If the player is returning, they should determine their position and the return to be made according to the situation.

Finally, in the last five to ten seconds, the player must first do some visualization work as well as perform a precise physical routine. When serving, the player must visualize the serve they are about to hit. When receiving, the player must visualise the return they would like to play. Finally, after the visualization, the player should perform the physical routine (during about five to seven seconds). For example, the player could bounce the ball a few times or take a deep breath and relax the shoulders. This routine should be completely identical for each sequence.

\section{METHODOLOGY AND PROCEDURE}

This mental development programme was conducted with two young (male) elite tennis players. These players were respectively 13 and 14 years old and were ranked among the top twenty players in their age category in the province of Quebec. The programme lasted eight weeks. First, six training sessions were devoted to learning the mental routine to be performed between exchanges. Then, the players took part in three different competitive situations: a practice match, a league match and a provincially sanctioned tournament.

Each training session lasted two hours. The first sessions served, among other things, to establish a bond of trust with the subjects. A contract was signed by both parties (player and coach). We also explained very clearly, in a theoretical way, each step of the mental routine to be performed between points. The aim was really to make sure that the players understood perfectly what they had to do, but also that they adhered to the process and that they were convinced that this technique would improve their game in the end. This is an extremely important step in a process of change on a mental level. On a practical level, during the subsequent sessions, the players experimented with several on-court exercises to improve their ability to deal with the mental routine.
One of the key exercises in this process was active on-court work. This exercise takes about 40-50 minutes. It involves playing points between the two players. However, for half of the exercise (20-25 minutes), the same player will serve during all the points. The server must then alternate between the left and right diagonals. The players do not keep score during this exercise. They just play points against each other, of course, trying to perform the mental routine they have learned.

The coach's role is to follow the players on the court during this mental routine (the 25 seconds between exchanges). The players must then mention aloud everything that happens during this routine. The players must first tell the coach why they react the way they do to the point they have just played. Then they should say (out loud) what type of serve they are about to perform. Finally, they should mention their physical routine that they will perform before serving. For example, this physical routine can be, like Denis Shapovalov's, two throws between the legs followed by four bounces on the floor. After that, the players serve and play the point. Then the process is repeated when the rally ends. The coach will also have to do the same process with the returning player. It is therefore more efficient to do this exercise with two coaches at the same time (one following the server and the other following the returner). However, it is also possible to do it by changing sides after a few interventions with the same player. After 2025 minutes, the roles are exchanged. The turner becomes the server, and the server becomes the turner.

Towards the end of the study, the players participated in three different competitive situations: a training match, a league match and a federally sanctioned tournament. For each of these situations, a very precise coding was carried out. After each exchange, it was noted whether or not the player had successfully completed the mental routine. It was then noted whether the point that followed was won or lost. In addition, it was noted when a player made a direct error. It was then possible to statistically correlate rallies lost due to unforced errors with successful and unsuccessful routines.

\section{RESULTS}

As far as the results are concerned, they are very conclusive. For the purposes of this article, the statistics of the two players under study have been combined and an overall average has been obtained. In total, 340 rallies were coded during the study. Here is an explanatory table including the different statistics under study:

\section{Table 1}

\begin{tabular}{lcc}
\hline 340 rallies evaluated & $\begin{array}{l}\text { Direct mistakes } \\
\text { after the routine }\end{array}$ & $\begin{array}{l}\text { Percentage of } \\
\text { points lost }\end{array}$ \\
\hline $\begin{array}{l}259 \text { routines judged } \\
\text { successful }\end{array}$ & 43 & $17 \%$ \\
$\begin{array}{l}76 \text { routines judged non } \\
\text { successful }\end{array}$ & 44 & $58 \%$ \\
\hline
\end{tabular}

\section{DISCUSSION}

This study was very revealing in terms of the importance of the mindset between rallies. Indeed, instilling a specific mental routine in our players can have immediate effects on their performance (Cox, 2011).

A similar study to this one also looked at this factor. Morais and Gomez (2019) worked with eleven players aged between 
11 and 14 years, ten boys and one girl. They focused on the serving routine and wanted to find out if including a specific serving routine (both physical and mental) would increase the players' performance in their serving games. Like in our research, the results of this study were very revealing. Indeed, the number of games won on serve increased from $25 \%$ to $55 \%$ after the introduction of the service routine.

Several other studies have looked at the importance of the mind in tennis. Many researchers have used a questionnaire in their various studies. For instance, Cowden (2016) used "The mental toughness inventory (MTI; Middleton et al., 2011)". This questionnaire measures 12 different dimensions of mental toughness such as perseverance, task focus, goal commitment and stress minimisation. 43 elite junior players from South Africa were invited to participate in the study. The average age was 13.6 years. Immediately after completing the questionnaire, the players were thoroughly coded within a tournament match. They were evaluated on more than 20 specific criteria such as percentage of break points saved, percentage of first serves in break point situations, percentage of critical points lost due to an unforced error, percentage of critical points won on return by hitting a winning shot, etc. After tallying the results, the researcher was able to come up with several interesting findings. He was able to state that there was a partially significant correlation on several dimensions. The one that stood out the most was the one that evaluated the percentage of critical points won in service. So, also based on the questionnaire filled out at the outset, it was concluded that those with high mental strength were more likely to win the critical points on serve. These players also had a high level of self-confidence and the natural advantage they had in serving gave them the additional mental weapons to win most of the crucial points.

As we can see from the scientific literature of the last few years, instilling a mental routine as well as various specific psychological strategies can only lead the player to an overall progression of his level of play. However, it is important to know your athletes well in order to apply the appropriate approach when carrying out mental interventions. Even if many techniques are fairly universal, it is important to know the personality of our players in order to establish an effective helping relationship and specially to establish a relationship of trust that will last over time.

\section{CONCLUSION}

The mental aspect is paramount to success in sport and this is even more valid for our growing youth. Living in a society of performance, anxiety is more and more present in our daily life. This is why the mental aspect must be of paramount importance in the learning and sport development of our young people.

Indeed, given the very high rates of psychological distress observed in our society (Picard \& al., 2007), it would be relevant to conduct more research that verifies to what extent the mental strategies used by athletes could also be useful for young people in general. I therefore encourage the entire scientific community working in this field to get involved in order to exploit this field of activity, which is, for me, captivating, exciting, but above all extremely important.

\section{REFERENCES}

Cowden, R. (2016). Competitive performance correlates of mental toughness in tennis: A preliminary analysis. Perceptual and Motor Skills, 123(1), 341-360.

Cowden, R. et Meyer-Weitz, A. (2016). Self-reflection and self-insight predict resilience and stress in competitive tennis. Social behavior and personality, 44(7), 1133-1150.

Cowden, R., Meyer-Weitz, A. et Asante, O. (2016). Mental toughness in competitive tennis: Relationships with resilience and stress. Frontiers in psychology, 7(320), 322-346.

Gould, D., Medbery, R., Damarjian, N. et Lauer, L. (1999). A survey of mental skills training knowledge, opinions, and practices of junior tennis coaches. Journal of applied sport psychology, 11, 28-50.

Mamassis, G. et Doganis, G. (2004). The effects of a mental training program on juniors pre-competitive anxiety, self-confidence, and tennis performance. Journal of applied sport psychology, 16, 118-137.

Morais, C. et Gomes, A. (2019). Pre-service routines, mental toughness and performance enhancement of young tennis athletes. International journal of sport psychology, 50(2), 176-192.

Picard, L., Claes, M., Melançon, C. et Miranda, D. (2007). Qualité des liens affectifs parentaux perçus et détresse psychologique à l'adolescence. Enfance, 59(4), 371-392.

Vaillant, J-P (2008). Tennis. Pensez comme un champion. Mode d'emploi pour gagner. Paris : Édition Amphora.

Wolfhenden, L. et Holt, N. (2005). Talent development in elite junior tennis: Perception of players, parents, and coaches. Journal of applied sport psychology, 17(2), 108-126.

\section{Copyright (C) 2021 Maxime Rome-Gosselin

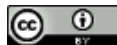 \\ This text is under a Creative Commons BY 4.0 license}

You are free to Share - copy and redistribute the material in any medium or format - and Adapt the content - remix, transform, and build upon the material for any purpose, even commercially under the following terms:

Attribution: You must give appropriate credit, provide a link to the license, and indicate if changes were made. You may do so in any reasonable manner, but not in any way that suggests the licensor endorses you or your use. 